\title{
Prevalence and morphometric features of fossa navicularis on cone beam computed tomography in Turkish population
}

\author{
N. Ersan \\ Department of Dentomaxillofacial Radiology, Yeditepe University Faculty of Dentistry, Turkey \\ [Received: 15 February 2017; Accepted: 17 March 2017]
}

Background: The objective of this study is to determine the prevalence and morphometric features of fossa navicularis, a close radiographic anatomic variation of canalis basilaris medianus of the basiocciput, in a Turkish population, using cone beam computed tomography (CBCT).

Materials and methods: The study group consisted of 723 patients (female: 420, male: 303) having CBCT scans. The patients had no syndromes, history of neurological diseases or surgery in the area of interest. On the images that revealed a fossa navicularis, the depth, length, and width measurements were performed, and were compared to the age and gender of the patients. The shape and number of fossa navicularis were also recorded.

Results: Fossa navicularis was identified in 48 (6.6\%) patients. Among these patients, 19 were female (4.5\% of all female patients), whereas 29 were male (9.6\% of all male patients), and their age ranged between 10 and 68 years (mean age: $34.0 \pm 18.7$ ). No significant difference was found between genders and age groups in terms of depth, length, and width measurements $(p>0.05)$. In 39 (5.4\%) patients, fossa navicularis presented oval in shape.

Conclusions: Even though the prevalence of fossa navicularis was found to be higher than previously reported, it still seems to be rare. Anatomical structure of the fossa navicularis can be studied effectively on CBCT images. (Folia Morphol 2017; 76, 4: 715-719)

Key words: cone beam computed tomography, radioanatomy, cranium, morphometry, fossa navicularis magna

\section{INTRODUCTION}

Fossa navicularis is an anatomical variation demonstrating as a bony, notch-like dehiscence in the basiocciput, on the inferior aspect of the clivus. Synonyms of this entity include fossa pharyngea, large pharyngeal fossa, keyhole defect, longitudinal or transverse segmentations, fossa navicularis magna and canalis basilaris medianus, with terminological overlapping [13]. In most cases, fossa navicularis is discovered in radiological examination as an incidental finding [1]; indicated by typically well-corticated margins.

Cone beam computed tomography (CBCT) is a reliable method for evaluating bony structures [5], and is recommended as a dose-sparing technique for maxillofacial imaging [6]. CBCT images demonstrate regions of the skull base, which are not within the area of interest. Therefore, dentomaxillofacial radiolo- 

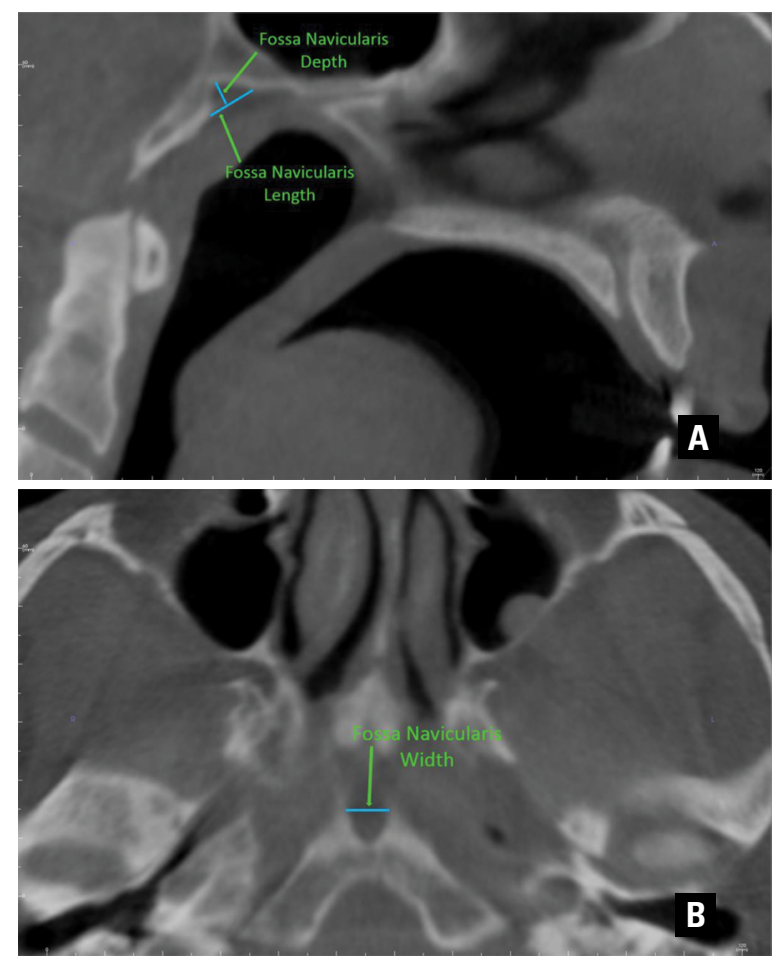

Figure 1. A. Depth and length measurements of fossa navicularis on the sagittal plane from the deepest portion; B. Width measurement of fossa navicularis on the axial plane from the same point.

gists must identify and report anatomical variations in order to prevent unnecessary further evaluation.

Fossa navicularis requires no intervention. Hence, knowledge of the anatomy of the area is necessary for the interpretation of pathological and anatomical variations. No prior studies have investigated the prevalence and morphometric features of fossa navicularis using CBCT. Due to lack of information in the literature, especially in the field of dentomaxillofacial radiology, this study aims to determine the prevalence and morphometric features of fossa navicularis, using CBCT.

\section{MATERIALS AND METHODS}

This retrospective study was conducted according to the principles of the Declaration of Helsinki. A total of 723 subjects (420 females, 303 males, with an age range of 10-89 years), who underwent CBCT examination for dentomaxillofacial indications between the years of 2010-2014, were included in the study. Individuals had no syndromes, history of neurological diseases or surgery in the area of interest. Written informed consent was obtained from all patients/legal guardians prior to imaging with $C B C T$.

$\mathrm{CBCT}$ imaging was conducted using an ILUMA CBCT device (Imtec Corporation, Oberursel, Germany; $120 \mathrm{kVp}, 3.8 \mathrm{~mA}$, and a voxel size of $0.2 \mathrm{~mm}$, with an exposure time of $40 \mathrm{~s}$ ). The image analysis and measurements were performed on Invivo5 dental software (Anatomage, San Jose, CA).

Fossa navicularis, if present, was detected on sagittal plane by scrolling through the image around the midsagittal area of anterior side of clivus. Once detected, depth and length was measured on the sagittal plane from the deepest portion (Fig. 1A). Subsequently, navigator of the software was placed on the area of interest and on the axial plane, width of the fossa navicularis was also measured from the same point (Fig. 1B). Besides, the shape was described as oval or round (Fig. 2).

\section{Statistical analysis}

SPSS version 22 for Windows (IBM SPSS, Turkey) was used for statistical analysis. In addition to the descriptive statistical methods, normality of the data

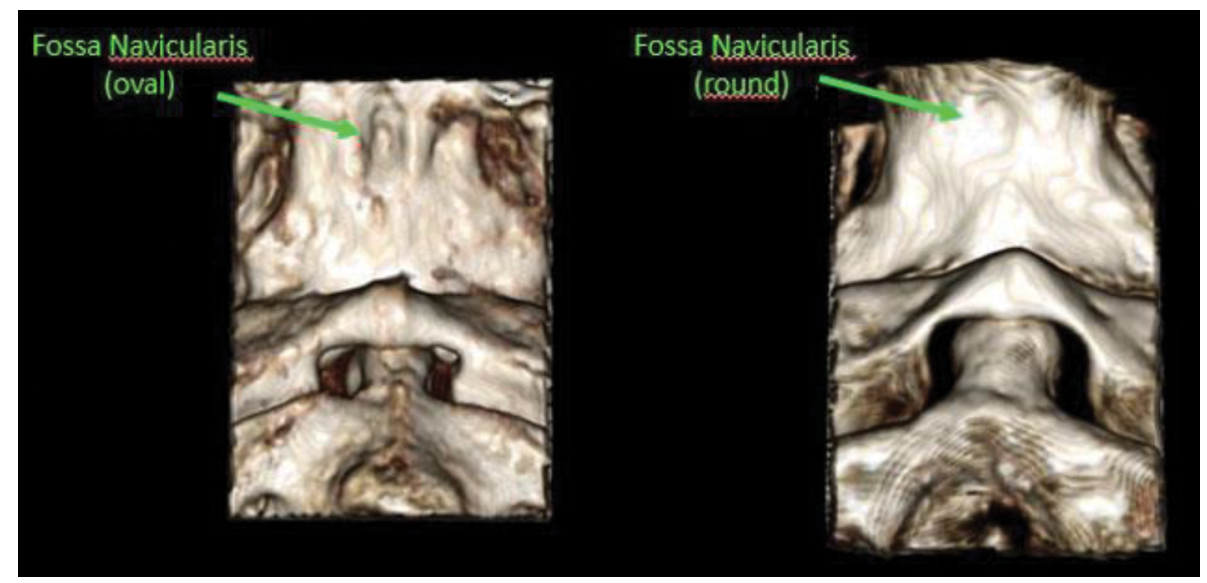

Figure 2. Three-dimensional cone beam computed tomography image demonstrating the shape of the fossa navicularis as oval and round. 
Table 1. Distribution of patients with a fossa navicularis according to age groups and gender

\begin{tabular}{|c|c|c|c|c|c|c|c|c|}
\hline & \multicolumn{7}{|c|}{ Age groups } & \multirow{2}{*}{$\begin{array}{c}\text { Total } \\
(\mathrm{n}=723)\end{array}$} \\
\hline & $\begin{array}{c}10-19 \\
(n=149)\end{array}$ & $\begin{array}{c}20-29 \\
(n=130)\end{array}$ & $\begin{array}{c}30-39 \\
(n=97)\end{array}$ & $\begin{array}{c}40-49 \\
\text { (n = 82) }\end{array}$ & $\begin{array}{c}50-59 \\
(n=131)\end{array}$ & $\begin{array}{c}60-69 \\
(n=90)\end{array}$ & $\begin{array}{c}>69 \\
(n=44)\end{array}$ & \\
\hline Female $(n=420)$ & $8(1.1 \%)$ & $0(0.0 \%)$ & $2(0.3 \%)$ & $2(0.3 \%)$ & $4(0.5 \%)$ & $3(0.4 \%)$ & $0(0.0 \%)$ & $19(2.6 \%)$ \\
\hline Male $(n=303)$ & $11(1.5 \%)$ & $6(0.8 \%)$ & $2(0.3 \%)$ & $2(0.3 \%)$ & $5(0.7 \%)$ & $3(0.4 \%)$ & $0(0.0 \%)$ & $29(4.0 \%)$ \\
\hline Total & $19(2.6 \%)$ & $6(0.8 \%)$ & $4(0.6 \%)$ & $4(0.6 \%)$ & $9(1.2 \%)$ & $6(0.8 \%)$ & $0(0.0 \%)$ & $48(6.6 \%)$ \\
\hline
\end{tabular}

Table 2. Comparison of the depth, length and width measurements of fossa navicularis according to gender and age groups

\begin{tabular}{|c|c|c|c|c|c|c|c|c|c|c|c|}
\hline & \multirow[b]{2}{*}{$\begin{array}{c}\text { Total } \\
(n=48)\end{array}$} & \multirow[b]{2}{*}{$\begin{array}{l}\text { Female } \\
(n=19)\end{array}$} & \multirow[b]{2}{*}{$\begin{array}{c}\text { Male } \\
(n=29)\end{array}$} & \multirow{3}{*}{$\mathbf{p}^{*}$} & \multicolumn{6}{|c|}{ Age groups } & \multirow{3}{*}{$\mathbf{p}^{* *}$} \\
\hline & & & & & $\begin{array}{c}10-19 \\
(n=19)\end{array}$ & $\begin{array}{l}20-29 \\
(n=6)\end{array}$ & $\begin{array}{c}30-39 \\
(n=4)\end{array}$ & $\begin{array}{l}40-49 \\
(n=4)\end{array}$ & $\begin{array}{c}50-59 \\
(\mathrm{n}=9)\end{array}$ & $\begin{array}{l}60-69 \\
(n=6)\end{array}$ & \\
\hline & $\begin{array}{c}\text { Min-Mlax } \\
\text { Mean } \pm \text { SD }\end{array}$ & $\begin{array}{c}\text { Min-Max } \\
\text { Mean } \pm \text { SD }\end{array}$ & $\begin{array}{c}\text { Min-Max } \\
\text { Mean } \pm \text { SD }\end{array}$ & & $\begin{array}{c}\text { Min-Mlax } \\
\text { Mean } \pm \text { SD }\end{array}$ & $\begin{array}{c}\text { Min-Max } \\
\text { Mean } \pm \text { SD }\end{array}$ & $\begin{array}{c}\text { Min-Max } \\
\text { Mean } \pm \text { SD }\end{array}$ & $\begin{array}{c}\text { Min-Max } \\
\text { Mean } \pm \text { SD }\end{array}$ & $\begin{array}{c}\text { Min-Max } \\
\text { Mean } \pm \text { SD }\end{array}$ & $\begin{array}{c}\text { Min-Max } \\
\text { Mean } \pm \text { SD }\end{array}$ & \\
\hline \multirow{2}{*}{ Depth } & $1.2-6.8$ & $1.3-6.8$ & $1.2-4.7$ & \multirow{2}{*}{0.382} & $1.2-6.8$ & $1.3-2.4$ & $1.7-2.8$ & $1.6-2.8$ & $1.3-4.8$ & $1.4-2.6$ & \multirow{2}{*}{0.449} \\
\hline & $2.2 \pm 1.0$ & $2.5 \pm 1.2$ & $2.1 \pm 0.8$ & & $2.2 \pm 1.2$ & $1.7 \pm 0.4$ & $2.2 \pm 0.5$ & $2.2 \pm 0.5$ & $2.8 \pm 1.3$ & $2.0 \pm 0.5$ & \\
\hline \multirow{2}{*}{ Length } & $2.0-10.4$ & $2.0-10.4$ & $2.6-9.6$ & \multirow{2}{*}{0.131} & $3.0-10.4$ & $3.2-7.9$ & $5.0-8.6$ & $4.4-7.2$ & $2.0-9.3$ & $2.6-7.9$ & \multirow{2}{*}{0.676} \\
\hline & $5.8 \pm 2.2$ & $6.2 \pm 2.4$ & $5.6 \pm 2.0$ & & $6.1 \pm 2.5$ & $4.9 \pm 1.7$ & $6.5 \pm 1.7$ & $6.1 \pm 1.2$ & $6.1 \pm 2.4$ & $4.8 \pm 2.1$ & \\
\hline \multirow{2}{*}{ Width } & $2.0-8.9$ & $2.0-8.9$ & $2.8-7.3$ & \multirow{2}{*}{0.464} & $3.0-8.9$ & $2.8-5.1$ & $3.5-6.7$ & $4.8-6.0$ & $2.0-7.3$ & $3.0-5.5$ & \multirow{2}{*}{0.567} \\
\hline & $4.7 \pm 1.4$ & $5.0 \pm 1.7$ & $4.5 \pm 1.0$ & & $4.9 \pm 1.5$ & $4.0 \pm 0.8$ & $4.5 \pm 1.5$ & $5.4 \pm 0.5$ & $4.8 \pm 1.7$ & $4.2 \pm 1.0$ & \\
\hline
\end{tabular}

*Mann Whitney U test; ** One-way ANOVA test; SD — standard deviation

Table 3. Distribution of patients demonstrating a fossa navicularis according to the shape of the fossa navicularis

\begin{tabular}{llcccccccc}
\hline & & \multicolumn{7}{c}{ Age groups } & Total \\
\cline { 3 - 7 } & & $\mathbf{1 0 - 1 9}$ & $\mathbf{2 0 - 2 9}$ & $\mathbf{3 0 - 3 9}$ & $\mathbf{4 0 - 4 9}$ & $\mathbf{5 0 - 5 9}$ & $\mathbf{6 0 - 6 9}$ & $\mathbf{6 9}$ & \\
\hline \multirow{2}{*}{ Oval } & Female & $6(0.8 \%)$ & $0(0.0 \%)$ & $2(0.3 \%)$ & $2(0.3 \%)$ & $4(0.5 \%)$ & $2(0.3 \%)$ & $0(0.0 \%)$ & $16(2.2 \%)$ \\
& Male & $9(1.2 \%)$ & $3(0.4 \%)$ & $2(0.3 \%)$ & $2(0.3 \%)$ & $4(0.5 \%)$ & $3(0.4 \%)$ & $0(0.0 \%)$ & $23(3.1 \%)$ \\
\multirow{2}{*}{ Round } & Female & $2(0.3 \%)$ & $0(0.0 \%)$ & $0(0.0 \%)$ & $0(0.0 \%)$ & $0(0.0 \%)$ & $1(0.1 \%)$ & $0(0.0 \%)$ & $3(0.4 \%)$ \\
& Male & $2(0.3 \%)$ & $3(0.4 \%)$ & $0(0.0 \%)$ & $0(0.0 \%)$ & $1(0.1 \%)$ & $0(0.0 \%)$ & $0(0.0 \%)$ & $6(0.8 \%)$ \\
\hline
\end{tabular}

distributions was evaluated by Kolmogorov-Smirnov test. Differences in measurements between genders were tested by Mann-Whitney $U$ test, whereas between age groups by one-way ANOVA test. The intraobserver agreement was assessed using the intraclass correlation coefficient that was found between 0.88 and 0.94 . Statistical significance was set at $p<0.05$.

\section{RESULTS}

CBCT images of 48 (6.6\%) individuals demonstrated a fossa navicularis. Fossa navicularis was observed in male patients more frequently than in female patients $(4.0 \%$ and $2.6 \%$, respectively; Table 1).

In 25 (3.4\%) of the patients it was less than $2 \mathrm{~mm}$ in depth, and in the remaining 23 (3.2\%) it had a depth of more than $2 \mathrm{~mm}$. No significant difference was found between genders and age groups in terms of depth, length and width measurements (Table 2).

In terms of shape, 39 (5.4\%) were found to be oval, whereas 9 (1.2\%) of them were round (Table 3 ). 
All the fossa navicularis were demonstrated as a single bone cavity. Double pharyngeal fossa, which was previously demonstrated [11], was not encountered in the images of this study.

\section{DISCUSSION}

This is the first study that demonstrated the prevalence and morphometric features of fossa navicularis by using a CBCT device. The percentage of fossa navicularis identified in this study (6.6\%), was found to be higher than the percentage reported in previous studies performed on dry skulls or CT images of the patients. Fossa navicularis was reported by Rossi [11] in 55 (1.5\%) of 3712 dried skulls, by Romiti [10] in $9(0.9 \%)$ of 990 skulls, by Rizzo [9] in 7 (2.1\%) of 335 skulls, by Ray et al. [8] in $3(1.49 \%)$ of 202 skulls, whereas by Cankal et al. [2] in 26 (5.3\%) of the 492 dry skulls and in 16 (3\%) of the 525 CT scans.

Cankal et al. [2] found the incidence of a fossa navicularis of $2 \mathrm{~mm}$ in depth in dry skulls (2.9\%) was nearly the same as detected in patients (3.0\%) and thereby concluded that the incidence of fossa navicularis was higher in anatomical studies than it is in radiological studies due to the difficulties in detecting a fossa navicularis of $2 \mathrm{~mm}$ depth in $\mathrm{CT}$ images.

However, the incidence they found in dry skulls was higher than in other previous studies performed on dry skulls. This discrepancy suggests that there could be an effect of race-related differences on the results.

In our study, the percentage of fossa navicularis was found higher than previously demonstrated. Maybe because this study was carried on CBCT images that have a slice thickness of as minimum as $0.1 \mathrm{~mm}$, technique more accurate than in CT studies.

Additionally, in our study the patients were Turkish. Cankal et al. [2], who were also Turkish, did not provide any information on the origin of the population in their study. It is probable that in case they studied also in Turkish population, this would support the idea that the origin of the patients has effect on the prevalence and that the prevalence of fossa navicularis is higher in Turkish population.

In the reported cases, the depth varied from $2 \mathrm{~mm}$ to $5.5 \mathrm{~mm}$, the length from $7 \mathrm{~mm}$ to $13 \mathrm{~mm}$, and the width from $5 \mathrm{~mm}$ to $8 \mathrm{~mm}$ [1]. Ray et al. [8] measured the depth as $0.5 \mathrm{~mm}>$ in 1 , and $0.5 \mathrm{~mm}<$ in 2 skulls, and they found the mean length and width as $5 \mathrm{~mm}$ and $3.66 \mathrm{~mm}$, respectively. Cankal et al. [2] reported that depth ranged between $1.10 \mathrm{~mm}$ and $4.11 \mathrm{~mm}$, length between $1.79 \mathrm{~mm}$ and $9.33 \mathrm{~mm}$, and width between $1.50 \mathrm{~mm}$ and $3.90 \mathrm{~mm}$, on dry skulls. They did not provide any information on the fossa navicularis measurements on CT images. In our study, the depth varied from $1.2 \mathrm{~mm}$ to $6.8 \mathrm{~mm}$, the length from $1.2 \mathrm{~mm}$ to $6.8 \mathrm{~mm}$, and the width from $2.0 \mathrm{~mm}$ to $8.9 \mathrm{~mm}$.

Fossa navicularis was usually reported as oval in shape with the major axis in the sagittal plane; less frequently, it was perfectly round [1], as also seen in our study.

There are few references to the fossa navicularis in recent anatomy textbooks or scientific papers. It was stated that Testut was the first to describe the fossa navicularis in 1921 on radiographs of a patient [13]. Collins [3] referred to it as the fossa pharyngea, whereas Currarino [4] used the term canalis basilaris medianus. In the literature, the formation of fossa navicularis is still controversial. This structure contains the smaller pharyngeal fossa and may be related to notochord remnant in the roof of the pharynx that prevents complete ossification of the basiocciput [1]. It was also suggested that it might be a variant of incomplete canalis basilaris medianus (inferior basiocciput type) since they have radiographically identical features [13]. Differential diagnosis includes anatomical and pathological variations [2].

Previously, it was shown in some case reports that fossa navicularis might serve as a route for the spread of an infection from the oropharynx to the base of the skull $[4,7,12]$, in which complete recovery could be achieved with surgical obliteration of the bony defect [4]. Therefore, understanding the embryology and anatomy of bony variations may promote better diagnosis of disease in this region.

\section{CONCLUSIONS}

In conclusion, even though the prevalence of fossa navicularis was found to be higher than previously reported on dry skull and CT studies, it still seems to be rare. The anatomical structure of the fossa navicularis can be studied effectively on CBCT images. It could be a good technique for the analysis of the fossa navicularis compared to the dry skull and CT studies. Besides, the linear dimensions and shape of the fossa navicularis are applicable as reference standards for further investigation in the Turkish population. 


\section{REFERENCES}

1. Beltramello A, Puppini G, El-Dalati G, et al. Fossa navicularis magna. AJNR Am J Neuroradiol. 1998; 19(9): 1796-1798, indexed in Pubmed: 9802508.

2. Cankal F, Ugur HC, Tekdemir I, et al. Fossa navicularis: anatomic variation at the skull base. Clin Anat. 2004; 17(2): 118-122, doi: 10.1002/ca.10191, indexed in Pubmed: 14974099.

3. Collins $\mathrm{H}$. Frequency and distribution of fossa pharyngea in human crania. Am J Physical Anthropol. 1927; 11(1): 101-106, doi: 10.1002/ajpa.1330110106.

4. Currarino G. Canalis basilaris medianus and related defects of the basiocciput. AJNR Am J Neuroradiol. 1988; 9(1): 208-211, indexed in Pubmed:3124576.

5. De Vos W, Casselman J, Swennen GRJ. Cone-beam computerized tomography (CBCT) imaging of the oral and maxillofacial region: a systematic review of the literature. Int J Oral Maxillofac Surg. 2009; 38(6): 609-625, doi: 10.1016/j. ijom.2009.02.028, indexed in Pubmed: 19464146.

6. Ludlow JB, Ivanovic M. Comparative dosimetry of dental CBCT devices and 64-slice CT for oral and maxillofacial radiology. Oral Surg Oral Med Oral Pathol Oral Radiol Endod. 2008; 106(1): 106-114, doi: 10.1016/j. tripleo.2008.03.018, indexed in Pubmed: 18504152.
7. Prabhu SP, Zinkus T, Cheng AG, et al. Clival osteomyelitis resulting from spread of infection through the fossa navicularis magna in a child. Pediatr Radiol. 2009; 39(9): 995-998, doi: 10.1007/s00247-009-1283-9, indexed in Pubmed: 19415254.

8. Ray B, Kalthur SG, Kumar B, et al. Morphological variations in the basioccipital region of the South Indian skull. Nepal J Med Scien. 2015; 3(2): 124-128, doi: 10.3126/ njms.v3i2.13457.

9. Rizzo A. Canale cranio faringeo, fossetta faringea, interparietali e preinterparietali nel cranio umano. Monogr Zool Ital. 1901; 12: 241-252.

10. Romiti G. La fossetta faringea nell'osso occipitale dell'uomo. AttiSoc Toscana Sci Nat. 1890: 11.

11. Rossi G. Il canale cranio-faringeo e la fossetta faringea, ricerche antropologiche. Monogr Zool Ital. 1891; 2: 117-122.

12. Segal N, Atamne E, Shelef I, et al. Intracranial infection caused by spreading through the fossa naviclaris magna - a case report and review of the literature. Int J Pediatr Otorhinolaryngol. 2013; 77(12): 1919-1921, doi: 10.1016/j. ijporl.2013.09.013, indexed in Pubmed: 24148862.

13. Syed AZ, Mupparapu M. Fossa navicularis magna detection on cone-beam computed tomography. Imaging Sci Dent. 2016; 46(1): 47-51, doi: 10.5624/isd.2016.46.1.47, indexed in Pubmed: 27051639. 